\title{
A posição de docentes da educação básica acerca da militarização de escolas públicas em Goiás
}

\author{
The position of teachers of basic education about \\ militarization of public schools in Goiás \\ La posición de profesores de educación básica sobre la militarización de las \\ escuelas públicas en Goiás \\ ERLANDO DA SILVA RÊSES \\ WESLEI GARCIA DE PAULO
}

\begin{abstract}
Resumo: Os colégios da polícia militar do Estado de Goiás atendem estudantes da Educação Básica e são fruto de uma parceira entre a Secretaria de Educação e a Secretaria de Segurança Pública, iniciada em 1999 na cidade de Goiânia. Outras escolas de regiões periféricas e com alto índice de criminalidade receberam a implantação da militarização. Este texto apresenta uma pesquisa num colégio estadual de Valparaíso de Goiás com o objetivo de saber a posição de docentes acerca deste modelo de gestão escolar por meio de uma enquete por questionário com sete questões abertas para 12 professores/as da escola. Além de pesquisa bibliográfica, utilizamos pesquisa e análise documental e a categorização com o uso da Análise de Conteúdo das respostas ao questionário. Os resultados apresentaram a aprovação do modelo, enfatizando a valorização da hierarquia para o respeito, a disciplina para a efetividade das aulas e o controle sobre posturas e comportamentos de estudantes no ambiente escolar.
\end{abstract}

Palavras-chave: Militarização da Educação; Profissão Docente; Controle Social

\begin{abstract}
The colleges of the military police of the state of Goiás serve students of Basic Education and are the result of a partnership between the Secretariat of Education and the Secretariat of Public Security, which started in 1999 in the city of Goiânia. Other schools in peripheral and high-crime regions received militarization. This text presents research in a state school of Valparaíso de Goiás aiming to know the position of teachers about this model of school management through a questionnaire with seven questions open to 12 teachers of the school. In addition to bibliographic research, we used documentary research and analysis and categorization using the Content Analysis of questionnaire responses. The results presented the approval of the model, emphasizing the appreciation of the hierarchy for respect, the discipline for the effectiveness of classes and the control over postures and behaviors of students in the school environment.
\end{abstract}

Key words: Militarization of Education; Teaching profession; Social control

Resumen: Los colegios de la policía militar del estado de Goiás atienden a estudiantes de la Educación Básica y son el resultado de una asociación entre la Secretaría de Educación y la Secretaría de Seguridad Pública, iniciada en 1999 en la ciudad de Goiânia. Otras escuelas en regiones periféricas y de alta criminalidad recibieron militarización. Este texto presenta una investigación en 
una escuela estatal de Valparaíso de Goiás con el objetivo de conocer la posición de los maestros sobre este modelo de gestión escolar a través de un cuestionario con siete preguntas abiertas a 12 profesores/as de la escuela. Además de la investigación bibliográfica, utilizamos la investigación y el análisis documental y la categorización utilizando el Análisis de Contenido de las respuestas al cuestionario. Los resultados presentaron la aprobación del modelo, enfatizando la valoración de la jerarquía por el respeto, la disciplina para la efectividad de las clases y el control sobre las posturas y comportamientos de los estudiantes en el ambiente escolar.

Palavras-chave: Militarización de la educación; Profesión docente; Control social

\section{INTRODUÇÃO}

O processo de militarização das escolas goianas se iniciou em 1999 com o governo de Marconi Perillo, mas voltou a tomar força em 2015, quando se ampliou o número de escolas estaduais que aderiram à militarização. A implementação se deu por força de lei estadual, como política pública, e houve mudança curricular, como a implantação de disciplinas como Noções de Cidadania e exercícios físicos militares incorporados na Educação Física. As unidades escolares são administradas pela PM do Estado de Goiás, mas a equipe de professores é a mesma da rede estadual.

Os colégios da polícia militar do Estado de Goiás (CPMG) atendem estudantes da segunda fase do Ensino Fundamental e Ensino Médio. Esses colégios não fazem parte do Sistema Colégio Militar do Brasil (SCMB), o qual é subordinado ao Exército, mas são fruto de uma parceira entre a polícia militar goiana e a Secretaria Estadual de Educação de Goiás (SEDUCE), sendo um modelo singular no contexto brasileiro.

As cidades goianas que receberam as escolas possuem as mesmas características socioculturais, como o fato de serem regiões periféricas com alto índice de criminalidade, segundo o Atlas da Violência 2018 (CERQUEIRA et al., 2018). O Atlas mostra que as políticas públicas de segurança pública de Goiás e as ações sociais destinadas à redução da violência da última década não surtiram efeito ou, na melhor das hipóteses, fracassaram.

O professor da Universidade Federal de Goiás (UFG), Dijaci David de Oliveira, em seu artigo "As escolas militares: o controle, a cultura do medo e da violência", publicado na obra de Oliveira e Silva (2016), reforça o caráter imperativo da medida como forma de ampliar a agenda neoliberal e de ofensa aos movimentos sociais. Para Oliveira (2016), existem várias razões que favorecem as escolas militares, entre elas, o discurso do medo e da violência, que apresenta os adolescentes como perigosos. 
O Munípio de Valparaíso de Goiás compõe a RIDE e está localizado na área Metropolitana de Brasília (AMB) ${ }^{1}$ e Entorno Sul do Distrito Federal (DF) ${ }^{2}$. A Região Integrada do Desenvolvimento do Distrito Federal e Entorno - RIDE foi criada por meio da Lei Complementar no 94 e sancionada pelo Presidente da República em 19 de fevereiro de 1998. Formam a RIDE, além do Distrito Federal, 19 Municípios do Estado de Goiás e 3 do Estado de Minas Gerais (BRASÍLIA, 2007).

O Município de Valparaíso-GO possui um Índice de Desenvolvimento Social (IDS) bem abaixo da média do Estado de Goiás e está entre os 100 municípios populosos, com baixa receita per capita e alta vulnerabilidade socioeconô $\neg$ mica, segundo publicação 'g100' da Frente Nacional de Prefeitos (FNP), de dezembro de 2013 (RÊSES, 2015a).

Os estudantes de escolas públicas do Estado de Goiás e da área metropolitana de Brasília-DF, como Valparaíso de Goiás-GO, são provenientes de famílias de baixa renda, com baixa escolaridade e com alto índice de desemprego, sendo marginalizados pela escassez de oportunidades e convivendo em salas de aulas lotadas em estruturas físicas precárias.

Segundo dados da Pesquisa Metropolitana por Amostra de Domicílios (PMAD 2017/2018) da Companhia de Planejamento do Distrito Federal (Codeplan),

Valparaíso-GO tem 164.664 habitantes, sendo um dos municípios mais populosos do Estado de Goiás (GDF, 2018).

A pesquisa do PMAD 2017/2018 apontou que o município conta com 53.817 domicílios urbanos tendo, em média, 3,06\% moradores por domicílio. A renda per capita real é de $R \$ 790,60$, sendo uma renda domiciliar real de $R \$ 2.391,53$ (GDF, 2018).

\footnotetext{
1 AMB - Àrea Metropilitana de Brasília compreende o Distrito Federal e 10 municípios, segundo critérios para enquadramento em aglomeração metropolitana: Luziânia, Valparaíso de Goiás, Cidade Ocidental, Novo Gama, Formosa, Planaltina de Goiás, Santo Antônio do Descoberto, Águas Lindas de Goiás, Alexânia e Padre Bernardo. Disponível em http://www.codeplan.df.gov.br/wp-content/uploads/2018/03/ Delimita $\%$ C3\%A7\%C3\%A3o-do-Espa $\%$ C3\%A7o-Metropolitano-de-Bras $\%$ C3\%ADlia-AMB.pdf. Acessado em 12 jul 2019.

2 Entorno Sul do DF é formado pelos municípios goianos de Valparaíso, Novo Gama, Cidade Ocidental, Luziânia, Cristalina, Águas Lindas e Santo Antônio do Descoberto (RÊESES, 2015).
} 
Dessa população, os dados mostram que apenas 1,11\% são analfabetos e 7,59\% possuem nível superior completo. Chama a atenção o fato de que, em $56,54 \%$ dos domicílios, há automóveis e o município é o primeiro em desigualdade social, atingindo $0,440 \%$ em grau de desigualdade medido pelo Índice de $\mathrm{GINI}^{3}$ (GDF, 2018).

Os últimos dados do censo do Instituto Brasileiro de Geografia e Estatística (IBGE) de 2016, mostram que, em Valparaíso de Goiás-GO, a média salarial dos trabalhadores formais não passa de dois salários mínimos $(1,9)$. O Índice de Desenvolvimento Humano (IDH) do município é de $0,746^{4}$ (BRASIL, 2016).

Os dados do IBGE demonstram que, apesar da alta escolarização de alunos entre seis e 14 anos (96,8\%), o Índice de Desenvolvimento da Educação Básica (IDEB) em 2015 era de 4,9 para os anos iniciais e de 4,1 para os anos finais no município (BRASIL, 2016).

No desenvolvimento do texto realizamos uma breve abordagem histórica do processo de militarização no Brasil e sua relação com a educação. Além de pesquisa bibliográfica, utilizamos pesquisa e análise documental em fontes oriundas da lei de criação do colégio militarizado pesquisado, o Projeto PolíticoPedagógico da escola, o Regimento Interno, o IDEB, jornais e periódicos da época e a grade curricular da parceria entre a SEDUCE e o Comando de Ensino da Polícia Militar de Goiás. Por fim, aplicamos uma enquete por questionário com sete questões abertas para 12 docentes da escola. A partir das repostas fizemos a categorização com o uso da Análise de Conteúdo.

3 O Índice de Gini, criado pelo matemático italiano Conrado Gini, é um instrumento para medir o grau de concentração de renda em determinado grupo.Ele aponta a diferença entre os rendimentos dos mais pobres e dos mais ricos. A medida é em percentagem com variação entre 0 e 1 , onde zero corresponde a uma completa igualdade na renda e um corresponde a uma completa desigualdade entre as rendas. Disponível em: http://desigualdade-social.info/indice-de-gini.html. Acessado em 12 jul 2019.

4 Índice de Desenvolvimento Humano (IDH) mede o nível de desenvolvimento humano dos países utilizando como critérios indicadores de educação (alfabetização e taxa de matrícula), longevidade (esperança de vida ao nascer) e renda (PIB per capita). O índice varia de zero (nenhum desenvolvimento humano) a um (desenvolvimento humano total). Países com IDH até 0,499 têm desenvolvimento humano considerado baixo, os países com índices entre 0,500 e 0,799 são considerados de médio desenvolvimento humano e países com IDH superior a 0,800 têm desenvolvimento humano considerado alto. Disponível em:https://www.terra.com. $\mathrm{br} /$ noticias/mundo/entenda-o-calculo-do-idh-e-seus-indicadores,9b65120115dc0cc756b529832aa733d1nls36v 2s.html. Acessado em 12 jul 2019. 


\section{HISTÓRIA E IDEOLOGIA MILITAR NA EDUCAÇÃO}

O processo de militarização não é algo novo no Brasil. Sua sistematizada interferência na educação, igualmente, não é nada novo. Desde os primeiros pensamentos sobre escola, instrução e ensino, sempre se evidenciou a forte presença e a influência militar na construção, consolidação e efetivação da educação.

Um nome de relevância nessa perspectiva de implementação militarizada na educação foi Benjamim Constant. Ele entrou para o exército em 1852, participou da Guerra do Paraguai e era um dos idealizadores do golpe que derrubou o Império de D. Pedro II, sendo, por isso, considerado um dos fundadores da República. Foi Ministro de Guerra e Ministro da Instrução Pública, Correios e Telégrafos do governo do Marechal Deodoro da Fonseca.

Benjamin Constant, conceituado e respeitado professor da Escola Militar - escola criada e mantida no Rio de Janeiro à época - determinou o lema da bandeira brasileira. A ideia veio das influências sobre ele dos ideários positivistas de Augusto Comte, que considerava a educação como prática essencial para a anulação de tensões sociais. Sendo assim, Constant encabeçou uma nítida reforma na educação do Brasil e publicou as obras "Memórias sobre a Teoria das Quantidades Negativas" e o "Relatório sobre a Organização do Ensino dos Cegos" (LINS, 1964).

$\mathrm{Na}$ década de 1850, o governo percebeu a situação que se configuraria no ensino da Real Academia, e desmembrou-a em dois estabelecimentos: o ensino militar, transferido para a Praia Vermelha, naquele estabelecimento que ficou conhecido como Escola Militar, e o ensino de matemática, ciências físicas e naturais e engenharia, aberto tanto a militares quanto a civis, com a implementação da Escola Central, conhecida, em 1874, como Escola Politécnica (LINS, 1964).

Devemos considerar que, já na primeira república, com a política café com leite, imperaram as práticas coronelistas em todo o país, especialmente em Goiás. Evidentemente, a escola era elitizada e voltada aos interesses dos coronéis, fortalecendo ideais militares como manutenção da soberania burguesa patriarcal.

Jappe (2013) lembra do pensamento positivista e da presença militar na sociedade. Desde que a valorização do capital começou a cortar os víveres do Estado, este recuou e abriu mão de setores cada vez mais amplos, que eram próprios de sua intervenção. Quando não houvesse mais tantos enfermeiros e professores no serviço público, haverla cada vez mais policiais. Em tempos de crise, o Estado não tem mais nada a oferecer aos seus cidadãos além de "proteção", 
e ele não tem, portanto, qualquer interesse em perpetuar a insegurança que cria a demanda por proteção. O Estado pode privar-se de todas as suas funções, com exceção da manutenção da ordem.

O autor enaltece Estado que se transforma de novo no que sempre foi em seus primórdios: um bando armado. As milícias se tornam polícias "regulares" em numerosas regiões no mundo, e as polícias se tornam milícias e bandos armados. Jappe (2013) explicita que por trás de toda essa retórica sobre o Estado e seu papel civilizador, há sempre, em última análise, alguém que esmaga a cabeça de outro ser humano, ou que, pelo menos, tem a possibilidade de fazê-lo.

Vicentini (2014) etnografou policiais militares (cabos e soldados) goianos atendidos pelo serviço de psiquiatria do Hospital da PM, e notou um conflito entre a caserna e a rua:

[É] possível afirmar que o contraste com o mundo dos civis, conforme asseverado, "baliza" o ingresso na ordem militar e a construção dessa nova identidade social. Enquanto a ordem militar é rigidamente organizada, moralizada, disciplinada e tida como exemplo a ser seguido, o mundo dos civis é frouxo, desregrado, permeado de vícios, imoral, sujo (VICENTINI, 2014,.p.65).

Quanto às atribuições, a PM é vista enquanto instituição "não pura" em relação ao Exército, tendo em vista o contato direto com civis, compreendidos enquanto "impuros" (VICENTINI, 2014, p. 66).

O contraste da PM em relação à Polícia Civil se dá pelo caráter disjuntivo da polícia brasileira. No caso da PM, a ela é reservado exclusivamente o policiamento ostensivo fardado com o objetivo de se preservar a ordem pública, ao passo que à Polícia Civil cabem o registro de ocorrências e as investigações criminais.

Distinguem-se em relação à estrutura, a normas administrativas e operacionais, à disciplina e ao salário (VICENTINI, 2014, p.67).

A repressão é essencial para que exista o controle do Estado e esse, por meio de seus aparelhos ideológicos, é responsável por transmitir os pensamentos e os desejos da classe dominante, com o objetivo de manter o status quo estabelecido, como nos elucida Althusser (1980), em "Aparelhos Ideológicos do Estado". O aparelho repressivo de Estado funciona por meio da violência e compreende o governo, a administração, o exército, a polícia, os tribunais, as prisões, etc, para se garantir a reprodução das relações de exploração no Estado capitalista e, também, para garantir as condições políticas do funcionamento dos aparelhos ideológicos de Estado (ALTHUSSER, 1980). 
$\mathrm{Na}$ escola contemporânea, por exemplo, a presença do sinal ou da sirene para iniciar as aulas, o uso do uniforme, as fileiras, a distribuição de cadeiras e mesas, o controle do diário com frequência, as disciplinas a serem cursadas, grade curricular e departamentos, nos remete à institucionalização militar na esfera educacional.

Não apenas a escola foi militarizada desde o princípio da república brasileira, a partir das concepções positivistas, como afirma Lins (1964), mas a escola reproduz toda a sociedade brasileira. Ela passa a desempenhar um papel diferente daquele para o qual fora incialmente criada. Agora a escola é um grande Panóptico de Bentham,

Espaço fechado, recortado, vigiado em todos os seus pontos, onde os indivíduos estão inseridos em um lugar fixo, onde os menores movimentos são controlados, onde todos os acontecimentos são registrados, onde um trabalho ininterrupto de escrita liga o centro e a periferia, onde o poder é exercido sem divisão, segundo uma figura hierárquica contínua, onde cada indivíduo é constantemente localizado, examinado e distribuído, isso tudo constitui um modelo compacto do dispositivo disciplinar (FOUCAULT, 2014, p. 192).

O Panóptico de Bentham é a figura arquitetural da composição da escola militarizada. O princípio é conhecido: na periferia, uma construção em anel; no centro, uma torre vazada, com janelas largas que se abrem sobre a face interna do anel. A construção periférica é dividida em celas, cada uma atravessando toda a espessura da construção, sendo que cada uma dessas celas possui duas janelas, uma para o interior, correspondendo às janelas da torre, outra para o exterior, permitindo que a luz atravesse a cela toda. Basta, então, colocar um vigia na torre central, e em cada cela trancar um louco, um doente, um condenado, um operário ou um escolar.

A garantia da ordem se dá por meio da disciplina e de punições. O que se espera dos estudantes é que não haja colas, barulho, conversas, dissipação. A multidão, massa compacta, local de múltiplas trocas, individualidades que se fundem, efeito coletivo, é abolida em proveito de uma colação de individualidades separadas.

Foucault (2014) lembra ainda que o jurista e filósofo inglês Jeremy Bentham, criador do panoptismo, idealiza que as instituições panópticas pudessem ser tão leves: fim das grades, fim das correntes, fim das fechaduras pesadas, basta que as separações sejam nítidas e as aberturas bem distribuídas.

Militarizar escolas públicas do Estado não era apenas uma ação deslocada do governo goiano, mas uma atitude eleitoreira e populista. O grande objetivo alcançado da medida governamental em militarizar escolas estaduais, há quase duas décadas em Goiás, é apresentar à sociedade uma gestão cujas palavras 
fundamentais são monitoramento e punição, que constituem formas de controle social capazes de "manter" a ordem estabelecida e vigente. Em nada a militarização das escolas goianas enfatiza algum aprimoramento pedagógico na construção do conhecimento por parte dos estudantes. Pelo contrário, a ação pode ser: "analisar os métodos punitivos não como simples consequências de regras de direito ou como indicadores de estruturas sociais; mas como técnicas que têm sua especificidade no campo mais geral dos outros processos de poder. Adotar em relação aos castigos a perspectiva de tática política" (FOUCAULT, 2014, p. 27).

A escola brasileira se estruturou com base no modelo taylorista, com uma rígida especialização das tarefas a serem executadas e, desse modo, o professor é visto como um especialista voltado apenas para a sala de aula, ou seja, é distanciado do processo de pensar e planejar a ação educativa, perdendo-se, portanto, a visão de totalidade inerente à prática pedagógica (RÊSES, 2015b).

$\mathrm{Na}$ escola militarizada, os estudantes são submetidos à vigilância e ao monitoramento a todo momento por meio da presença de militares armados num complexo educacional que mais lembra um quartel, com salas de aulas e professores de jalecos brancos. Isso induz a uma íntima relação de poder e submissão permanente.

Nada de criticidade nem de questionamentos; ao contrário, há uma formação de jovens que sabem que estão sendo vigiados e que, portanto, agem de maneira 'dócil', zelando pela manutenção do status quo. Ser observado sempre é uma forma impositiva de poder e disciplina, havendo possibilidade de ações punitivas. Ou seja, o medo impõe o 'respeito'.

Outro fato que também chama a atenção na Polícia Militar é a presença de discriminações, sejam raciais ou de gênero. Há democracia racial até o ponto em que o negro não se coloca em condição de disputar com o branco. Diferentemente da discriminação ocorrida nos Estados Unidos ou África do Sul, que se caracterizou por ser segregacionista, a discriminação no Brasil pode parecer não existir para os menos avisados, mormente por coexistirem negros e brancos no mesmo ambiente. Mas há, tacitamente, e, em alguns casos, explicitamente, delimitação social. O negro frequenta o mesmo espaço, porém não tem permissão para disputá-lo com aquele que se julga dominador (ARAÚJO, 2008)

Em sua pesquisa, Araújo (2008), realizando grupo focal, evidenciou, a partir das falas de policiais femininas, a visão machista/sexista de nossa sociedade refletida nas ações de alguns policiais. No grupo focal, uma sargento reclamou dos assédios diretos e indiretos de que foi vítima. Pelo fato de não ceder às investidas de alguns policiais, foi taxada de lésbica e sempre teve sua vida profissional dificultada por esses profissionais, sendo escalada em serviços chamados de 'boca podre', onde o estresse e a tensão são maiores e a quantidade 
de ocorrências também. A característica do dominador se revela nesse episódio: se não te domino, então te calo, para mostrar quem é o dominador. As qualidades e méritos das policiais mulheres são ignorados.

No grupo focal, foi revelado que há descontentamento entre o próprio grupo feminino, pois quando uma policial se destaca, sendo promovida ou fazendo um curso disputado, recebendo elogios, medalhas ou dispensas, as companheiras de farda comentam que ela tem ou deve estar na iminência de ter um 'caso' com algum superior. Também não há confiança de que elas sejam capazes de desempenhar a função policial militar. Esse desconforto aumenta quando a função é de comando (ARAÚJO, 2008).

A situação de discriminação contra a mulher parece ficar mais constrangedora quando se é negra, afirma Jurema Werneck (2007). Segundo dados colhidos no site 'Diálogos contra o racismo', as mulheres negras brasileiras estão entre os contingentes de maior pobreza e indigência do país, possuem menor escolaridade, apresentando uma taxa de analfabetismo três vezes maior que as mulheres brancas, além de menor expectativa de vida.

Outra rejeição muito forte por parte dos policiais militares se dá em relação ao policial homossexual. Os entrevistados, tanto oficiais quanto praças, não se sentiram bem em conversar sobre o assunto. Alguns admitem a existência de policiais homossexuais, mas alegam que não fica bem um Policial Militar com gestos femininos, pois a farda exige respeito. Um tenente coronel confidenciou que a homossexualidade, tanto masculina quanto feminina, enfraquece a moral da tropa, mas que há maior tolerância para homossexualidade feminina que para a masculina (ARAÚJO, 2008).

Além dessa questão, outro aspecto a ser questionado é o caráter público das instituições de ensino militarizadas, na medida em que "taxas simbólicas" são cobradas dos/as alunos/as, a exemplo de matrícula e fardamento militar, impossibilitando que a população em vulnerabilidade socioeconômica da região possa manter seus filhos e filhas na escola.

Frente ao exposto, cabe problematizar o impacto em esfera educacional da gestão do ensino por parte de uma instituição balizada por assimetrias de poder fundamentadas na violência. Assim sendo, o policial, sem formação profissional, não possui condições para desempenhar o ofício pedagógico de um professor. Na contramão disso, como forma de legitimar ainda mais o processo de militarização, foi promulgada, no último dia 4 de julho de 2019, pelo Senado Federal, a EMENDA CONSTITUCIONAL No 101 DO SENADO FEDERAL, DE 03 DE JULHO DE 2019 de autoria do senador e policial Alberto Fraga (DEM/DF), que regulamenta o acúmulo de cargos ao Policial Militar, que pode 
atuar agora também como professor. O modelo educacional militarizado em nada preconiza qualidade no ensino e fere diretamente preceitos constitucionais, como o fim da gestão democrática e o pagamento de taxas na escola pública.

\section{A POSIÇÃO DE DOCENTES SOBRE A MILITARIZAÇÃO DE ESCOLAS PÚBLICAS}

Nesta pesquisa utilizamos observação com presença na escola e diálogo informal com docentes, pesquisa documental e aplicação de questionário com docentes de um colégio estadual de Valparaíso de Goiás. Para o tratamento dos dados usamos a análise de conteúdo, com utilização de categorias.

No levantamento do perfil sociodemográfico dos questionários, podemos apresentar situações para compreender o perfil de cada docente que participou da pesquisa. Buscamos, com isso, compreender a totalidade em que se insere o investigado e, a partir de sua experiência pessoal, política e educacional, compreender como eles percebem a gestão militarizada nas escolas goianas e sua relação com a comunidade escolar.

$\mathrm{Na}$ observação realizada na escola e no contato com o corpo docente obtivemos a informação de que o procedimento mais apropriado para a investigação seria a enquete por questionário. Certamente, o atual cenário político brasileiro, em que o governo do Estado $^{5}$ e governo federal de Jair Bolsonaro (PSL) defendem a ampliação da militarização em todas as escolas, promoveu essa situação mais distanciada para a pesquisa de campo.

Das 12 pessoas entrevistadas na enquete por questionário, sete eram mulheres e cinco homens. Desse total, apenas três residiam em ValparaísoGO. Um outro mora no município de Cidade Ocidental-GO, três na região administrativa de Santa Maria-DF, outras três na região administrativa do GamaDF, uma na região administrativa de Águas Claras-GO e outras duas declararam morar em Brasília ou no Distrito Federal. Portanto, apenas quatro docentes moram em municípios goianos que formam a Área Metropolitana de Brasília (Cidade Ocidental e Valparaíso).

Outro fato relevante é que, dos 12 docentes, oito possuem contrato temporário com a rede pública de ensino goiano. Apenas quatro são efetivos por concurso público. Ficou evidente durante o preenchimento dos questionários que esses oito não gostariam de aprofundar muito no assunto da pesquisa, e que,

\footnotetext{
$5 \quad$ O governador atual é Ronaldo Caiado (DEM), mas as administrações anteriores, desde 1999, apoiaram a implementação e expansão das escolas militarizadas no Estado de Goiás: Marconi Perillo do PSDB (1999-2003 e 2003-2006); Alcides Modesto do PP (2006-2007 e 2007-2011); Marconi Perillo do PSDB (20112015 e 2015-2018) e José Eliton Júnior do PSDB ( 2018-2019).
} 
em geral, eram adeptos da gestão militarizada. Não havia muito interesse em polemizar nada, até porque sua condição precarizada de trabalho não permitiria muitos questionamentos ${ }^{6}$.

Quanto à formação acadêmica dos docentes da pesquisa o quadro é: um docente possuía somente graduação, cinco eram especialistas e outros seis tinham concluído mestrado ou estavam em fase de conclusão. A maioria lecionava Língua Portuguesa ou Matemática no colégio militarizado. Em relação à graduação dos docentes, quatro tinham formação em Letras, dois em Ciências Sociais e dois em Matemática. Os demais docentes apresentaram graduação em História, Pedagogia, Engenharia Mecânica, Economia e Biologia. Alguns professores apresentaram duas graduações.

Observamos que os docentes ministravam no colégio mais de uma disciplina, como no caso dos formados em Letras com habilitação em Português e Inglês; ou ainda aqueles que tinham duas graduações. Assim, observou-se que três ministravam Matemática e três ministravam Língua Portuguesa. Dois ministravam Inglês e dois História. Para cada uma das disciplinas, Ciências, Geografia, Biologia, Espanhol, Sociologia e Química, havia apenas um docente. Os investigados trabalhavam no Ensino Fundamental II e no Ensino Médio.

É interessante observar que todos os docentes possuem experiência em sala de aula. Desses, três estão no colégio militarizado a partir de 2019; três estão desde 2018; dois chegaram em 2016 e outros dois em 2017. Um docente está no colégio desde 2015, e apenas um trabalha no colégio antes da militarização, ou seja, desde 2012.

O questionário foi de sete questões e, a partir das respostas criamos categorias, observando a regularidade ou frequência das respostas para a definição da categoria. Algumas respostas foram reduzidas, mas tiveram sua essência e teor mantidos nos quadros seguintes.

6 Sugere-se uma nova pesquisa sobre este enfoque: Condição precarizada do trabalho docente em escola militarizada 


\section{Quadro 1 - Percepção sobre a gestão da escola}

\begin{tabular}{|c|c|}
\hline \multicolumn{2}{|c|}{ COMO VOCÊ PERCEBE A GESTÃO DA ESCOLA? } \\
\hline Categorias & Verbalizações \\
\hline Disciplina e Organização & 1. "O foco é a organização e disciplina." \\
& 2. "Disciplinada e organizada." \\
3. "Bem disciplinada e organizada." & 4. "Visa disciplina dos alunos." \\
& 5. "Competende dentro do âmbito pedagógico e disciplinar." \\
\hline Competência e & 1. "Gestão com muito profissionalismo." \\
Profissionalismo & "Organizada e suporte aos doscentes." \\
& 3. "Competente e oraganizada." \\
& 5. "Gestão militarizada com hierarquia militar. Um capitão cuidando do \\
administrativo e um civil no pedagógico." & "Segue normas da SEDUCE e Regimento próprio. Ás vezes as decisões são \\
& tomadas de forma coletiva." \\
6. "Firme e com objetivos."
\end{tabular}

Fonte: Pesquisa de campo

Partindo das categorias mencionadas, podemos perceber que os docentes deram ênfase à questão da organização implementada pela gestão militar. Essa compreensão foi determinada por uma escola que consegue impor disciplina entre os estudantes e isso passa a impressão de que a gestão é competente e age com profissionalismo. Um docente lembrou, entretanto, que a gestão não age de forma democrática. As decisões são, em sua maioria, tomadas de maneira unilateral pelo Comando e Direção e devem ser seguidas pelo colégio. Outro docente chamou a atenção para o papel transformador da educação, que em nada é lembrado pela militarização. Pelo contrário, ele deixa explícito que faltam políticas de conscientização por parte da gestão que resgatem ou trabalhem esse papel da educação, tão defendido por teóricos como Paulo Freire.

É importante ressaltar que o "profissionalismo da gestão", citado por alguns docentes, refere-se à possibilidade que os professores encontram de cobrar dos estudantes que as tarefas sejam realmente realizadas, que os alunos os respeitem e que as exigências sejam cumpridas, mesmo que por meio da imposição pelo medo. 


\section{Quadro 2 - Percepção sobre controle da docência}

\begin{tabular}{|c|c|}
\hline \multicolumn{2}{|c|}{ VOCÊ SE SENTE TILIDO(A), VIGIADO(A) OU CONTROLADO(A) NO EXERCÍCIO DA DOCÊNCIA? } \\
\hline Categorias & \multicolumn{1}{c|}{ Verbalizações } \\
\hline Cobranças e Resultados & $\begin{array}{r}\text { 1. "Não. Os alunos podem descrever qualquer ocorrido em sala aos militares." } \\
\text { 2. "Somos cobrados quanto aos resultados, prazos e conteúdos. Há liberdade } \\
\text { do método em sala de aula." } \\
\text { 3. "Somos supervisionados. Coisa boa. Supervisão pedagógica." }\end{array}$ \\
\hline Desconforto e Adaptação & $\begin{array}{r}\text { 1. "Não. Me adaptei as regras." "Não, mas a presença de pessoas amadas na escola me causa surpresa. } \\
\text { Postura sisuda me gera desconforto." } \\
\text { 3. "Não. Tenho liberdade no conteúdo." }\end{array}$ \\
\hline
\end{tabular}

Fonte: Pesquisa de campo

Aqui surgiram palavras como supervisionados, controlados e cobrados para exemplificar que os docentes são submetidos a apreciação militarizada durante o exercício da docência. Uma das respostas demonstrou que o investigado apenas aceitou porque se adaptou às regras. Outro respondeu que não se sente vigiado, e fez questão de comentar que os alunos tem total liberdade de descrever aos militares qualquer ação fora do esperado dentro de suas aulas.

Um docente se sente controlado em algumas situações, respondendo "às vezes", e outro deixou claro que a presença de militares armados dentro do ambiente escolar causava-lhe surpresa e gerava desconforto. Ele lembrou ainda da postura sempre sisuda dos militares fardados.

Fica evidente, nas respostas dos docentes, que as aulas são monitoradas, de maneira direta ou indireta com intervenção ou não da coordenação pedagógica. Uma postura ou um olhar são exemplos dessa interferência. 


\section{Quadro 3 - Percepção sobre a disciplina com os estudantes}

\begin{tabular}{|c|c|}
\hline \multicolumn{2}{|c|}{ COMO VOCÊ AVALIA A DISCIPLINA DE BASE MILITAR COM OS ESTUDANTES? } \\
\hline Categorias & Verbalizações \\
\hline Positiva e Impositiva & $\begin{array}{l}\text { 1. "Gera disciplina e alunos exemplares." } \\
\text { 2. "Positivo. Precisam de regras e rotina. Isso não tem nas familias." } \\
\text { 3. "Positiva e facilita o trabalho docente." } \\
\text { 4. "Disciplina muito intensa, mas ajuda no aprendizado em sala." } \\
\text { 5. "Positiva." } \\
\text { 6. "Boa e facilita o trabalho docente." } \\
\text { 7. "Boa, mas pode melhorar. Ainda há resistência às regras." } \\
\text { 8. "Falta carisma. As regras são cumpridas mais pela imposição e não de } \\
\text { vontade. Não dá para se negar tal obediência." } \\
\text { 9. "Importante para o bom andamento." }\end{array}$ \\
\hline Organização e Ordem & $\begin{array}{l}\text { 1. "Os alunos gostam de rotina. Se sentem importantes como Chefes de Truma } \\
\text { na limpeza e organização." } \\
\text { 2. "Importante para disciplina e ordem." }\end{array}$ \\
\hline
\end{tabular}

Fonte: Pesquisa de campo

Novamente, a maioria dos docentes revela a importância da disciplina para manutenção de boas aulas. Foram as categorias mais repetidas, seguidas também de organização e ordem. A grande maioria defende a gestão militarizada por conseguir atingir também estudantes quietos, com a valorização da rotina e o aproveitamento deles para o papel de vigilância e controle, como o desempenho do papel de chefe de turma.

É importante notar os mecanismos estruturais subjacentes à formação do espírito de corpo da PM. A hierarquia e a disciplina são dois princípios-chave para se compreender os signos estruturantes da PM. A hierarquia possui um caráter segmentador e organizador, ou seja, ela estrutura as condutas e as relações sociais dos indivíduos; a disciplina, por sua vez, garante a manutenção da hierarquia, bem como o sentimento de pertencimento a uma totalidade com o consequente aviltamento da esfera individual (VICENTINI, 2014).

O processo de militarização das escolas goianas envolve uma educação disciplinadora e controladora a serviço da docilidade do comportamento humano, o que exemplifica a teoria do controle social. Grosso modo, essa teoria designa um conjunto heterogêneo de recursos materiais e simbólicos que mantêm a ordem social, ou melhor, que garantem que os indivíduos comportem-se de maneira previsível e de acordo com as normas sociais vigentes em sua sociedade. Dessa forma, o controle social é a regulação do comportamento (e até do pensar) dos indivíduos dentro de uma conduta desejável por aqueles que governam e legislam sobre o grupo social controlado. 
Trata-se de um "conjunto de métodos pelos quais a sociedade influencia o comportamento humano, tendo em vista manter determinada ordem" (MANNHEIM, 1971, p. 178).

Um respondente pontuou que as regras são cumpridas e a ordem existe, porém isso ocorre pela imposição e não por convencimento pedagógico. O que há é obediência e não convencimento. Para esse docente falta carisma. Outro docente acha que essa manutenção da ordem pela gestão utilizando-se da base militar deveria ser mais humanizada. Ainda de acordo com o docente, poderíamos refletir sobre os fins e os objetivos almejados pelos militares.

\section{Quadro 4 - Percepção sobre formação de valores nos estudantes}

\begin{tabular}{|c|c|}
\hline \multicolumn{2}{|c|}{ QUE VALORES VOCÊ DESTACA NO AMBITO DA EDUCAÇÃO DOS ESTUDANTES? } \\
\hline Categorias & Verbalizações \\
\hline Disciplina e Respeito & $\begin{array}{r}\text { 1. "Disciplina e alunos exemplares." } \\
\text { 2. "Disciplina, compromisso, responsabilidade e cidadania." } \\
\text { 3. "Organização e disciplina por conta da presença dos militares." } \\
\text { 4. "Boa educação e disciplina." } \\
\text { 5. "Respeito e cidadania." } \\
\text { 6. "Valores hierárquicos em relação ao respeito." }\end{array}$ \\
\hline
\end{tabular}

Fonte: Pesquisa de campo

Os docentes destacaram valores normatizados e insistentemente lembrados e trabalhados em todo ambiente do colégio militarizado, seja no diálogo, nas reuniões ou nos regimentos. Disciplina, responsabilidade e compromisso são termos sistematicamente lembrados nas respostas.

Organização e cidadania também foram bem citados, ainda que um dos questionários tenha mostrado que essa organização e disciplina somente se efetivam mediante a presença de militares.

Alguns docentes, de maneira informal, mesmo comentando não concordar muito com a maneira como se trabalha no regime militarizado, ainda assim concordam que a organização e a disciplina por parte dos estudantes é fundamental para o aprendizado. 


\section{Quadro 5 - Percepção sobre currículo e conteúdo das disciplinas}

\begin{tabular}{|c|c|}
\hline \multicolumn{2}{|c|}{ COMO VOCÊ PERCEBE O CONTEÚDO DAS DISCIPLINAS E O SEU DESENVOLVIMENTO? COMO VOCÊ VÊ } \\
O CURRÍCULO?
\end{tabular}

Fonte: Pesquisa de campo

Os professores fizeram questão de afirmar que o currículo das disciplinas segue o mesmo em todas as escolas da rede estadual (SEDUCE). Todavia, um docente registrou que além das disciplinas previstas pela SEDUCE também são trabalhadas Noções de Cidadania, matéria essa que é lecionada por militar.

Os professores participantes não fizeram nenhuma avaliação sobre a disciplina lecionada por um militar, com orientações gerais que amparam a militarização e seus valores no ambiente educacional. Trabalhar a Ordem Unida, bater continência e hasteamento da bandeira não foram atividades problematizadas pelos investigados. Preferiram fazer críticas ao atual currículo, apontando que ele deixa de trabalhar conteúdos relevantes e que está defasado.

Os docentes não fizeram alusão à sua participação na elaboração do currículo ou à sua participação em atividades escolares e pedagógicas. Houve concordância com a imposição dos conteúdos, como os "aulões" para atingir índices numéricos, e submissão a ação pedagógica dos militares. 


\section{Quadro 6 - Percepção sobre meritocracia e organização}

\begin{tabular}{|c|c|}
\hline \multicolumn{2}{|c|}{ COMO VOCÊ AVALIA A MERITOCRACIA ENTRE ESTUDANTES? COMO VÊ A ORGANIZAÇÃO? } \\
\hline Categorias & Verbalizações \\
\hline Favorável e Tranquilo & $\begin{array}{c}\text { 1. "Totalmente favorável." } \\
\text { 2. "Fundamental para a ordem." } \\
\text { 3. "Necessário, inclusive, para a vida dos estudantes." } \\
\text { 4. "Os mais antigos ensinam os mais jovens." } \\
\text { 5. "Serve como incentivo aos alunos." } \\
\text { 6. "Algo bom, ajuda na responsabilidade." } \\
\text { 7. "Normal, já que o ambiente é militar." } \\
\text { 8. "Dificuldade de compreensão no início, mas depois os alunos passam a } \\
\text { aceitar." }\end{array}$ \\
\hline Negação & $\begin{array}{l}\text { 1. "Não vejo com bons olhos. Na educação precisa haver debates, crescimento } \\
\text { e interação social." } \\
\text { 2. "Não acredito em meritocracia. Hierarquia mantém respeito e disciplina." }\end{array}$ \\
\hline
\end{tabular}

Fonte: Pesquisa de campo

A meritocracia sempre foi um assunto polêmico nos debates educacionais. Não foi diferente nas respostas obtidas. Ainda que a grande maioria tenha citado meritocracia e hierarquização entre os estudantes como algo bom, favorável, positivo e necessário deve-se levar em consideração que docentes, que em respostas anteriores defenderam a gestão militarizada, agora se mostram contrários à meritocracia.

Uma das respostas questionou o caráter impositivo de meritocracia e hierarquia. Para esse docente, a educação precisa de debates, o que favorece o crescimento e a interação social. Ele não vê com bons olhos esse processo de hierarquia entre estudantes. Outro ponto interessante é perceber que outro docente, que defende a gestão militarizada, deixou "escapar" que o regime não é aceito tão tranquilamente. Em sua resposta, observou que, no início, sempre há dificuldade de compreensão por parte dos estudantes, mas que isso é superado com o passar do tempo.

Uma das respostas apontou que esse processo meritocrático e hierarquizado permite que alunos mais velhos ajudem os mais jovens na realização das tarefas. Todavia, a professora não soube explicar se isso ocorre pela importância da ajuda mútua ou por imposição, tendo em vista a hierarquização, que ocorre por meio da atuação da figura do chefe de turma, ou por meio da meritocracia, com a presença do aluno 'zero um'.

Destacar alunos por meritocracia, com base no regime militar, é um princípio do colégio e estimulado por todos. Além do chefe de turma, existe também o chefe geral, e o aluno destaque chamado 'zero um'. O chefe geral é 
um estudante do terceiro ano do Ensino Médio. Geralmente, o cargo é designado a alunos exemplares nas concepções militares de comportamento e notas. $\mathrm{O}$ mesmo ocorre com o zero um. A esses são reservadas premiações, como o alamar e certificados. No caso do zero um, haverá também exposição permanente desse aluno em uma galeria de fotos que ficará disposta na entrada central do colégio

\section{Figura 1- Exemplo de Alamar ${ }^{7}$}

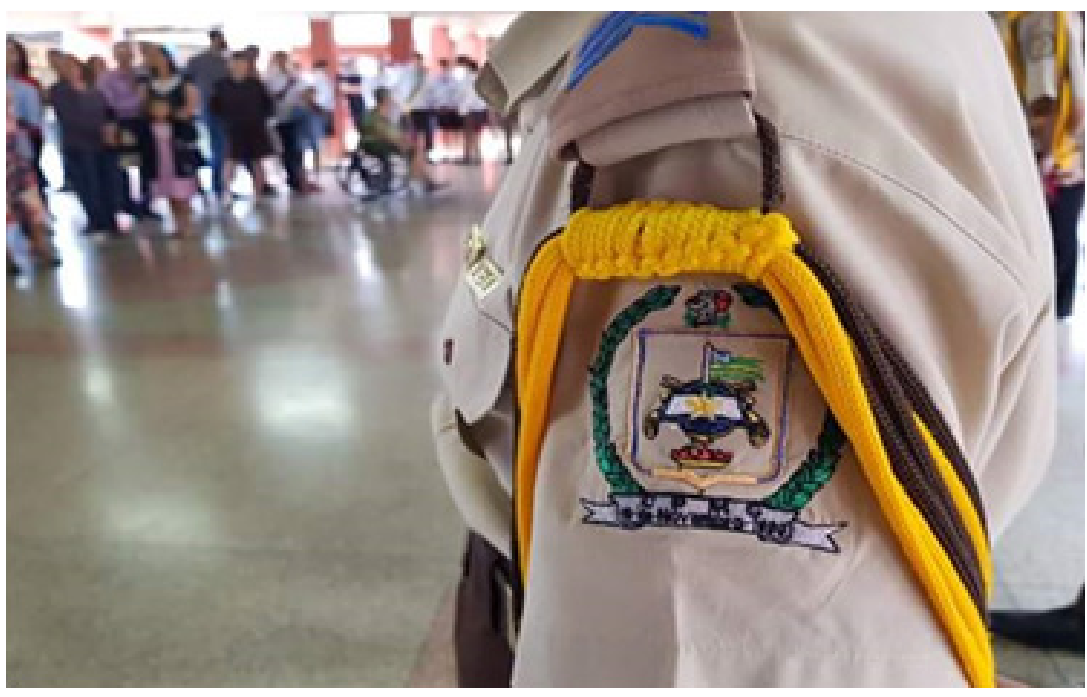

Fonte: Disponível em: mailto:facebook.com/@webcpmgfernandopessoa.Acessado em 12 jul 2019

A hierarquia do policiamento brasileiro pode ser compreendida ainda enquanto um fato social total, ou seja, os princípios estruturantes do universo simbólico militar perpassam todas as esferas da vida dos sujeitos, desde o campo do trabalho enquanto policial propriamente dito, até a esfera pessoal, fora da corporação. Segundo Vicentini (2014), é possível reconhecer o policial militar através de sua hexis corporal, ou seja, por meio da fala, dos gestos e dos comportamentos.

$7 \quad$ Cordão ou trança, geralmente de fio de seda, que guarnece a frente de uma peça de vestuário e o aperta, passando de um a outro lado da abotoadura. Peça de uniforme militar constituída de cordões entrelaçados, usada em certas corporações pelos oficiais de estado-maior e ajudantes-de-ordens. Disponível em: https://www.dicio.com.br/alamar/. Acessado em 16 nov 2019. 


\section{Figura 2 - Certificado do aluno zero um}

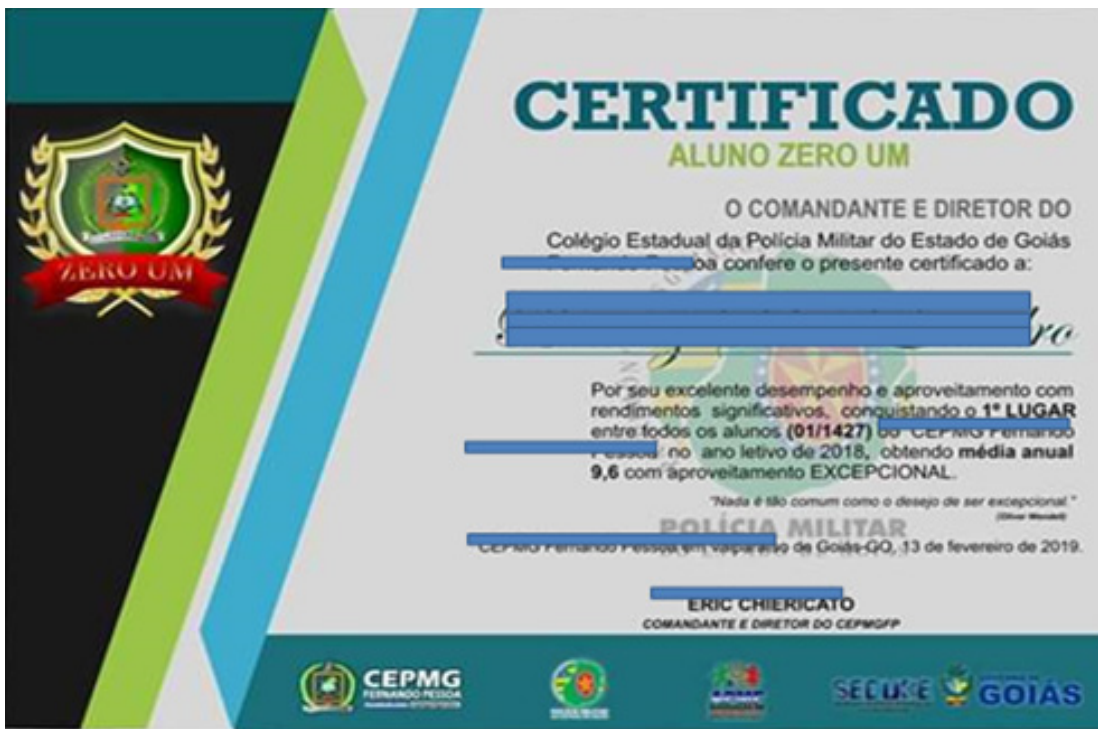

Fonte: Disponível em mailto:facebook.com/@webcpmgfernandopessoa. Acessado em 12 jul 2019.

O certificado de aluno zero um (Figura 2) é um modelo meritocrático instituído no ensino militarizado. Aqui, foi preservada a identidade do estudante que alcançou o "reconhecimento" no último período

\section{Quadro 7 - Conhecimento sobre avaliação da comunidade acerca da escola militarizada}

\begin{tabular}{|c|c|}
\hline \multicolumn{2}{|c|}{ COMO CONHECE A AVALIAÇÃO DA COMUNIDADE SOBRE A GESTÃo E O MODELO DA ESCOLA } \\
MILITARIZADA?
\end{tabular}

Fonte: Pesquisa de campo 
De acordo com o levantamento das repostas da última pergunta do questionário, segundo a concepção dos docentes, a comunidade aprova a gestão militarizada. A grande maioria aprova, apoia, elogia, admira e gosta do modelo do regime militar ao qual a gestão submete a escola. Para alguns é importante ressalvar que essa aprovação está diretamente ligada à questão da violência nas imediações do colégio e também nas suas dependências e à presença de drogas ilícitas.

Os professores avaliam o alto número de procura de vagas por parte dos pais como um dos indícios de que há aprovação entre a comunidade escolar em relação à militarização escolar. Em nenhum momento foi evidenciado que essa aprovação se respalda por aspectos pedagógicos ou mesmo por melhores índices nas avaliações de larga escala, um dos motivos, aliás, defendido pelo governo goiano para ampliar esse processo na rede estadual. O que leva à ampla defesa da gestão por parte dos pais é a sensação de segurança com o colégio cheio de militares armados.

O discurso da segurança pública tem-se tornado importante para muitos governantes. Por meio desses discursos, governos como o de Goiás podem ter maior controle sobre os movimentos sociais, pode ocorrer a ampliação da capacidade de monitoramento dos grupos de oposição, assim como de acompanhamento de setores apontados como socialmente incômodos como, por exemplo, as pessoas em situação de rua, migrantes estrangeiros de países considerados pobres ou arrasados, alem de movimentos sociais de contestação (OLIVEIRA; SILVA, 2016).

\section{CONSIDERAÇÕES FINAIS}

Desde a Constituição Federal de 1988 a gestão democrática da educação pública é um princípio constitucional, visando à integração e à participação dos entes envolvidos no contexto escolar, diferentemente do que vem sendo executado pela Polícia Militar nos colégios estaduais de Goiás.

Dois princípios são fundamentais para a caracterização e fortalecimento da gestão democrática: o princípio da autonomia e o princípio da participação da comunidade escolar. Isso se reflete na elaboração da proposta pedagógica da escola, na constituição dos conselhos escolares e na existência e atuação de grêmios estudantis. Sem esses elementos há uma grande tendência para a presença da chamada cultura do medo, do adestramento, com objetivos tecnicistas, por meio da imposição e da participação de pessoas portando armas no ambiente educacional. 
Consideramos a elaboração do Projeto Político Pedagógico o principal instrumento para o exercício da autonomia e da participação escolar e, desse modo, o principal instrumento para a realização de uma gestão democrática na escola. Concebemos gestão democrática não apenas como a eleição direta para gestores, e sim como um conjunto de ações que valorizem e estimulem a participação coletiva de todos atores que estão diretamente envolvidos com a escola; independentemente de como essa gestão democrática é estabelecida pelos sistemas de ensino, seja por prova, lista tríplice ou por eleição do gestor ou equipe gestora. Contudo, para a legitimação, é fundamental que, para o cargo de diretor po diretora, haja eleição direta com a participação ativa da comunidade escolar. Em Goiás, inclusive, existe a previsão de essa eleição ser substituída pela indicação unilateral de um militar da reserva para gerenciar o espaço escolar.

A luta pela cidadania no campo educacional, diferentemente da visão de cidadania dada pelos militares nos colégios militarizados, segundo Frigotto, Gadotti e Romão (1997), é a mesma luta pela cidadania que constrói a emancipação humana no conjunto das lutas sociais - pela terra, pela distribuição de renda e reforma agrária, por emprego e remuneração digna, pelo direito à saúde, educação, trabalho, seguro desemprego e aposentadoria.

Assim, parece-nos que a militarização de escolas estaduais visa tão somente à promoção de uma "cura" social, banindo a criminalidade. Existe, nesse contexto, uma total inversão de valores, segundo a perspectiva deste trabalho, em que a vítima - o estudante excluído e marginalizado - passa a ser tratado como potencial criador do caos e da desordem, precisando de intervenção repressora para tornar-se "socialmente aceitável".

O governo goiano e os partidos de sua base aliada decidiram pela militarização como medida repressora de manutenção da ordem, a partir de uma política pública, desconhecendo os estudos educacionais, que pontuam outras políticas públicas, como educação integral e politécnica, além do fomento à cultura e aos esportes como alternativas ao combate à criminalidade. Uma triste realidade que, fatalmente, resulta em terríveis lacunas de aprendizagem desde a alfabetização. Para além disso, os estudantes sofrem com a distorção idade/série e a ausência de políticas públicas educacionais que visam não apenas aos resultados avaliativos finais, mas sobretudo, êxito no processo ensino-aprendizagem

A própria PM reconhece que sua formação é para a repressão e não para o trato com a sociedade civil. Policiais militares treinados para o embate com uso de armas e viaturas. Sua postura denota constante ambiente de ataque ou defesa: portanto, não há nada que possa caracterizar esse tipo de profissional enquanto um gestor de escola. Para muitos policiais, inclusive, o caminho seria justamente pela desmilitarização da polícia. 
Outro ponto de total desacordo com a Constituição Federal é a cobrança de "taxas voluntárias" mensais e a matrícula mediante sorteio. Tais situações divergem daquilo que está elencado na Carta Magna sobre o mecanismo de gratuidade da escola pública e da oferta de vagas para todos.

A própria organização da PM, etnografada e pesquisada por muitos especialistas, alguns da própria corporação, apresenta indícios de problemas na formação militar daqueles que se propõem estar gerenciando um espaço educacional, inclusive lecionando, como no caso da disciplina Noções de Cidadania. Policiais são treinados para cumprir ordens, bater continência, combater o crime e agir com repressão. Vivem o conflito entre a caserna e a rua. Não possuem liberdade de expressão, de opinião e de luta pelos próprios direitos via associações e sindicatos. Sofrem com discriminação racial, homofobia e racismo no interior dos quartéis. Portanto, não possuem as condições necessárias para trabalhar em escolas, lidando diretamente com crianças, adolescentes e jovens.

Não é papel da Polícia Militar a direção de escola pública. A pesquisa detectou docentes apoiando a gestão militarizada escolar, a disciplina militarizada e a meritocracia. Disciplina que valoriza decorar conteúdos e cumprir regras. Esses docentes estão trabalhando em condições precarizadas, sem garantias estatutárias e trabalhistas, aderindo ao regime sob a ameaça do medo imposto por militares para a resolução dos problemas. Inclusive, há imposição aos docentes de não participar de assembleias da categoria ou aderir a greves.

Pensando nos policiais tambem enquanto classe trabalhadora, é importante a luta pela liberdade de expressão, de livre associação sindical e política, de luta pelo desarmamento e pela desmilitarização; pelo fim da discriminação e por autonomia. Essa polícia não está apta a dirigir unidades escolares. Essa função precisa ser desempenhada por aqueles que conhecem a educação, sobretudo a educação pública e a comunidade em torno da escola. É inadmissível um ambiente excludente e competitivo na escola, onde os 'melhores' sobressaem em detrimento do processo de ensino-aprendizagem de forma isonômica e que renegue os conflitos sociais.

O processo de militarização está intimamente ligado à sociedade capitalista, sendo que a escola é um espaço privilegiado de lutas de classes; assim, segundo alguns autores marxistas como Gramsci, Saviani e Lukács, ela resulta de uma divisão de classes, passando a ciência e o conhecimento a ser propriedade do capital na luta de classes. Nessa perspectiva, as consequências são o enfrentamento de classes e a limitação do indivíduo.

O combate à criminalidade e às desigualdades sociais se faz com mais investimentos na educação pública, na estrutura organizacional e estrutural das escolas, no conhecimento e na pesquisa científica, na difusão dos desportos e das 
artes como processo educativo e nunca na manutenção de ordem e controle social por meio do medo e da imposição de uma farda e uma arma. A escola não precisa de armas, precisa é de mais livros.

\section{REFERÊNCIAS}

ALTHUSSER, Louis. Ideologia e Aparelhos Ideológicos do Estado. Lisboa: Editorial Presença,1980.

ARAÚJO, M. Mobilidade Social, Multiculturalismo ou Discriminação na Polícia Militar. Brasília: Fortium, 2008.

BRASIL. Instituto Brasileiro de Geografia e Estatística (IBGE). Censo Demográfico de 2016. IBGE, 2016. Disponível em: www.ibge.gov.br. Acesso em: 12 jul 2019.

BRASÍLIA. CODEPLAN. Anuário Estatístico do Distrito Federal. Brasília: CODEPLAN, 2007.

CERQUEIRA, D. et al. Atlas da Violência 2018. Rio de Janeiro: IPEA, Fórum Brasileiro de Segurança, 2018.

FOUCAULT, Michel. Vigiar e Punir. 41ª ed. Petrópolis/RJ, 2014.

FRIGOTTO, G; GADOT'TI, M.; ROMÃO, J. E. Autonomia da escola: princípios e propostas. São Paulo: IPF/Cortez, 1997.

GDF - Governo do Distrito Federal. CODEPLAN. Pesquisa Metropolitana por Amostra de Domicílios (PMAD -2017/2018). Relatório Parcial (preliminar), 2018.

JAPPE, A. Violência, mas para quê? Tradução de Robson J.F de Oliveira. São Paulo, SP: Hedra, 2013.

LINS, Ivan. M. de B. Positivismo no Brasil. Rio de Janeiro. Editora Brasiliana, 1964. 
MANNHEIM, K. Sociologia Sistemática: uma introdução ao estudo da sociologia. $2^{a}$ Ed. São Paulo: Pioneira, 1971.

OLIVEIRA, Dijaci David de. As escolas militares: o controle, a cultura do medo e da violência. In: OLIVEIRA, I. C.; SILVA, V. H. V. de F. (orgs.). Estado de Exceção Escolar: uma avaliação crítica das escolas militarizadas. Aparecida de Goiânia: Escultura produções editoriais, 2016. p. 41-51.

RÊSES, Erlando da Silva; SILVA, Luis Alves da. Universidade de Brasília e Movimentos Sociais na periferia da Metrópole: parceria no Entorno Sul do DF. In: RÊSES, Erlando da Silva (org.). Universidade e Movimentos Sociais. Belo Horizonte, MG: Fino Traço, 2015a. p. 87-115

RÊSES, Erlando da Silva. De Vocação para Profissão: Sindicalismo Docente da Educação Básica no Brasil. Brasília: Paralelo 15, 2015b.

VICENTINI, Cláudia. Corpo fardado: adoecimento mental e psíquico na Polícia Militar goiana. Goiânia: Editora UFG, 2014.

WERNECK, Jurema. O Samba Segundo as Ialodês: mulheres negras e a cultura midiática. Tese de Doutorado em Comunicação e Cultura, Universidade Federal do Rio de Janeiro, . 2007.

ERLANDO DA SILVA RÊSES é Doutor em Sociologia pela Universidade de Brasília (UnB). É professor da Faculdade de Educação (FE) e do Programa de Pós-Graduação em Educação da UnB (PPGE). Líder do Grupo de Estudos e Pesquisas sobre Materialismo Histórico-Dialético e Educação (CONSCIÊNCIA) da FE/UnB. Membro do Grupo de Estudos e Pesquisas sobre o Trabalho (GEPT) do Departamento de Sociologia da UnB. Autor, co-autor ou organizador das obras: De Vocação para Profissão: Sindicalismo Docente da Educação Básica no Brasil (Ed. Paralelo 15, 2015); Universidade e Movimentos Sociais (Ed. Fino Traço, 2015); Sociologia no Ensino Médio: Cidadania e Representações Sociais de Professores e Estudantes (Ed. Fino Traço, 2016); Educação de Jovens e Adultos Trabalhadores - Políticas e Experiências da Integração à Educação Profissional (Ed. Mercado de Letras, 2017) e Ciganidade e Educação Escolar Saber Tradicional e Conflito Étnico (Tagore Editora, 2018). E-mail: erlando@ unb.br 
WESLEI GARCIA DE PAULO é Mestre em Educação pelo Programa de PósGraduação em Educação da Universidade de Brasília (PPGE/ UnB). Graduado em Pedagogia pela Universidade Luterana do Brasil (2009). Especialista em Docência no Ensino Superior pela Faculdade Apogeu. Professor da Secretaria de Educação do Distrito Federal e do Instituto de Ciências Sociais e Humanas -ICSH - CESB. E-mail: professorweslei50@gmail.com

Recebido em setembro de 2019

Aprovado em setembro de 2019 